\title{
Short term evaluation of the hamstring graft diameter after $A C L$ reconstruction
}

\author{
D. Costa Astur ${ }^{1,2}$, D. Pires², T. Parente ${ }^{2}$, P. Debieux ${ }^{1,2}$, C. Cohen Kaleka ${ }^{2}$, A. Skaf ${ }^{3}$, \\ M. Cohen ${ }^{1,2}$ \\ 1 Departamento de Ortopedia e Traumatologia, Escola Paulista de Medicina (EPM), Universidade Federal de São \\ Paulo (UNIFESP), São Paulo, SP, Brazil \\ 2 Instituto Cohen, São Paulo, SP, Brazil \\ 3 Instituto Alta, São Paulo, SP, Brazil
}

\section{CORRESPONDING AUTHOR \\ Diego Astur \\ Departamento de Ortopedia \\ e Traumatologia, Escola \\ Paulista de Medicina (EPM), \\ Universidade Federal de São \\ Paulo (UNIFESP), São Paulo, \\ SP, Brazil \\ E-mail: mcastur@yahoo.com}

DOI

10.32098/mltj.01.2019.01

\begin{abstract}
SUMMARY
Background. Graft embodiment process that occurs in the twelve weeks following reconstruction surgery is well described. However, the short-term performance characteristics of graphs, in terms of graft size and diameter, used in anterior cruciate ligament reconstructions is currently unknown. The purpose of this study was to measure the diameter of quadruple hamstring autograft with an MRI at two weeks post-op, before it undergoes any of the ligamentization process, and to compare it with the intra-operative graft measure. Material and methods. A prospective, observational study design was used. The MRI measured hamstring graft diameter at two weeks post-op from 38 study participants was compared to intraoperative diameter measurement of hamstrings graft during the ACL reconstruction surgery. Coronal plane T2 imaging was used to capture images in the intercondylar region near the tibial tunnel. Results. The average of the intra-operative graft diameter measurements was $7.9 \mathrm{~mm}$ (SD: $0.7 \mathrm{~mm}$; range: $6.5-9 \mathrm{~mm}$ ). The average post-operative measurement obtained via MRI imaging within two weeks post-op was $7.1 \mathrm{~mm}$ (SD: $0.8 \mathrm{~mm}$; range: $5.1-8.6 \mathrm{~mm}$ ). There was a significant decrease in the diameters of the graft over the first two weeks postoperatively $(\mathrm{p}<0.001)$. Conclusions. The diameters of quadruple hamstrings knee grafts used for reconstructions of the anterior cruciate ligament decreased by $9.68 \%$ on average between the moment of the surgery and two weeks after surgery. This information can be used to guide graft preparation, reconstruction planning, rehabilitation and post-operative counseling of the patient as to their risk of rupture.
\end{abstract}

\section{KEYWORDS}

anterior cruciate ligament; ACL graft measure; MRI; ligamentization; bamstring graft

\section{INTRODUCTION}

The anterior cruciate ligament (ACL) is an important primary knee stabilizer, and its main functions are to limit anterior translation and internal rotation of the tibia $(5,6,10,20)$. When injuries to this ligament occur, the use of a graft to restore articular function is necessary and indicated. Several graft options have been described including allografts, patellar or quadricipital autologous tendons, but semitendinosus and gracilis flexor muscles are more frequently used. $(2,8,12)$ Regardless of the type of graft used for reconstruction, all undergo a process known as ligamentization, in which the graft matures through revascularization and remodeling $(2,13,20)$. However, little is known about how the graft evolves in terms of hypertrophy, hypotrophy, elongation or shortening in the immediate post-operative period. It is known that graft embodiment and the early stages of ligamentization process start immediately after ACL reconstruction, and ends after one to three years after surgical procedure, but the exact sequence of the ligamentization process is still poorly understood $(7,19,21)$.

The purpose of this study was to measure the diameter of quadruple hamstring autograft with an MRI, before it undergoes any of the ligamentization process, and compare with the intra-operative graft measure. This comparison provid- 
ed valuable information about the immediate changes to the graph in terms of diameter and size. The hypothesis is that the ligament diameter decreases in the short-term.

\section{MATERIALS AND METHODS}

Institutional review board approval was obtained before the initiation of the study. A prospective and observational study was conducted from April 2015 to April 2017. A total of 38 patients underwent an arthroscopic, anatomic ACL reconstruction. Patients were included in the study if they were between 18 and 45 years of age; submitted to ligament reconstruction using a quadruple hamstring autograft; femoral fixation with a cortical button (Retrobuttom $^{\circledR}$, Arthrex-Naples, USA), and tibial fixation with a bio-interference screw (Biocomposite ${ }^{\mathrm{TM}}$, Arthrex-Naples, USA); and who underwent post-operative evaluation with MRI imaging within two weeks following surgery. Patients were excluded if they were less than 18 years of age and more than 45 years of age; underwent previous ACL reconstruction surgery; were found to have concomitant meniscal injury or associated ligamental injury of the same knee; and those treated with graft or fixation types other than those previously mentioned.

All surgeries were performed by the same surgeon (MC). The hamstring tendons were harvested through a $3-\mathrm{cm}$ anteromedial skin incision. Next, the transportal anatomic ACL reconstruction using the harvested quadruple-thickness hamstrings graft was performed, and fixed with a tibial interference screw and femoral extra-cortical fixation with a cortical button. Posterior drawer test and initial manual tension maneuvers were performed during fixation of the graft on the tibial side with the interference screw to ensure proper tensioning. During graft preparation, three orthopaedic surgeons present during the surgical procedure

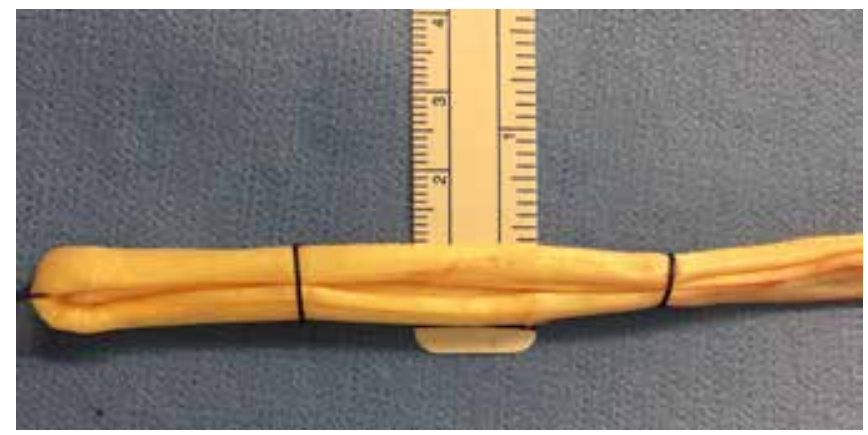

Figure 1 - Preparation of a quadruple hamstring graft. The graft measurements were recorded using a plastic rule among three different orthopaedic surgeon. If there was a consensus about less than $1 \mathrm{~mm}$ of difference, patient was included in the study. independently performed graft measures at its midpoint, to determine intra-operative diameter with an analog ruler. Patient was included only if all three measures were the same, or almost the same $(0.1 \mathrm{~cm}$ variation acceptable). The average value was recorded as the intra-op graft diameter size (figure 1). Additionally, pertinent patient data, including age, operative side, and the sizes of the tibial and femoral tunnels, were recorded.

A post-operative MRI on each reconstructed knee was requested and completed no more than two weeks after surgery, to evaluate and measure the quadruple hamstring graft diameter. No histological and structural graft changes were expected until this time $(9,14)$. Measures of the diameter of the ligament graft were taken by an independent radiologist in the coronal plane, with a T2 sequence centered on the intercondylar region next to the tibial tunnel with a $0.1 \mathrm{~mm}$ slice thickness (measurement accuracy), and the resultant measurements were compared with those taken intraoperatively (figure 2).
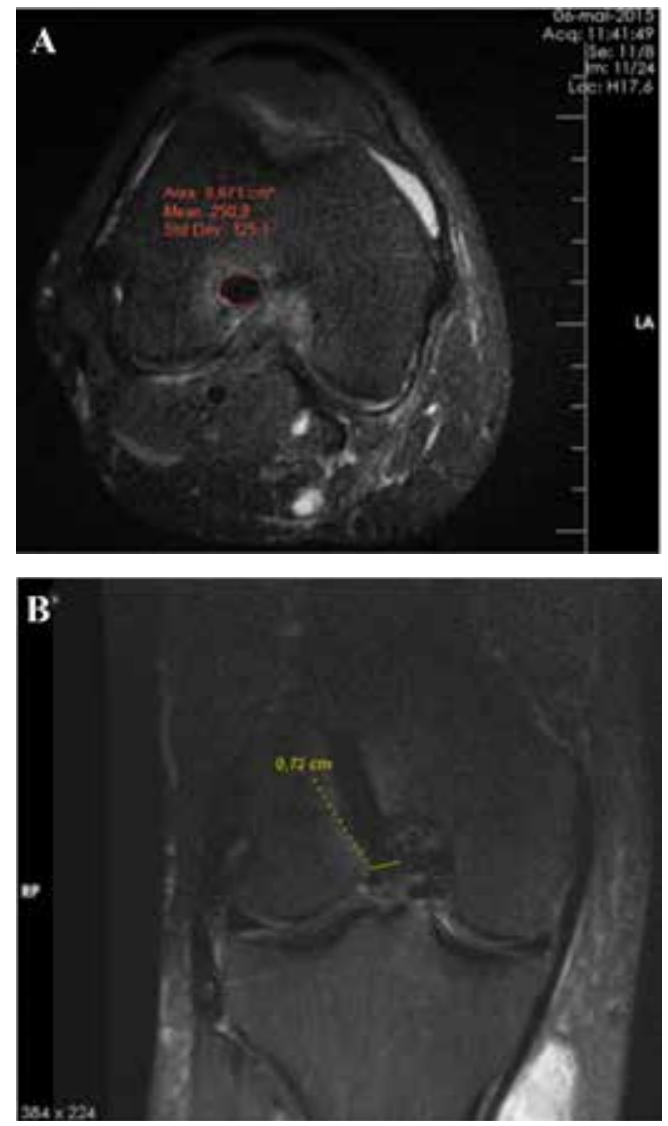

Figure 2 - Area and diameter of the hamstring graft measured in axial and coronal MRI images with a T2 fat-sat sequence centered on the intercondylar region next to the tibial tunnel. 
Immediately following surgery, patients began the prescribed rehabilitation program. Analgesia and soft tissue treatments for incisions, musculature and the patella to decrease fibrosis were continued, until discharge from the hospital. After two days, patients initiated weight bearing and wean from crutches as tolerated. Once range of motion improved from zero to 90 degrees flexion, the patients began straight leg raise exercises.

\section{Statistical analysis}

All variables were descriptively analyzed. For quantitative variables, the analyses were performed using minimum and maximum, average, and standard deviations values. Pearson's correlation coefficient was used to examine the correlations between variables. The level of significance used for the tests was $\mathrm{p}<0.05(5 \%)$. The sample power calculation was $99.6 \%$.

\section{RESULTS}

A total of 38 patients underwent ACL arthroscopic reconstruction and were included in the study. There were 20 male patients and 18 female patients. The mean patient age was 30 years (range 18-45). There were 21 right knees and 17 left knees treated and evaluated.

The mean graft diameter measured during surgery was $7.9 \mathrm{~mm}+/-0.7$ (range $6.5-9.0 \mathrm{~mm}$ ). The mean calculated from post-operative MRI measurements up to two weeks after surgery was $7.1 \mathrm{~mm}+/-0.8$ (range $5.1-8.6 \mathrm{~mm}$ ). There was a significant decline of $9.68 \%$ in the diameter of the neoligament from the time of surgery to the time of the post-surgery measurement $(\mathrm{p}<0.001)$. The differences between the graft diameter measurements during surgery and on imaging after surgery varied from -0.01 to $0.21 \mathrm{~mm}$ with an average of 0.08 $\mathrm{mm}+/-0.07$ (95\% confidence interval -0.04 to $0.11 \mathrm{~mm}$ ).

Regarding laterality, for the right knee, the mean intra-surgery graft diameter was $8.1 \mathrm{~mm}+/-0.06$ (range $7.0-9.0$ $\mathrm{mm}$ ), and the mean post-surgery measure was $7.5 \mathrm{~mm}$ $+/-0.06$ (range $6.5-8.6 \mathrm{~mm}$ ). For the left knee, the mean intra-surgery graft diameter was $7.5+/-0.08$ (range 6.5 - 9 $\mathrm{mm}$ ), and the mean post-surgery diameter was $6.4 \mathrm{~mm}+/$ 0.07 (range $5.1-7.2 \mathrm{~mm}$ ). Analysis of variance with repeated measures revealed that these changes were not significantly different according to surgery side $(\mathrm{p}=0.14)$. The right knees exhibited significantly greater averages at both time points (i.e., intra- and post-surgery) $(\mathrm{p}=0.009)$, and both sides exhibited a significant graft diameter decrease from the intra- to post-surgery measurements $(\mathrm{p}<0.001)$.

There was no significant difference between femoral and tibial tunnel size and graft size $(\mathrm{p}>0.05)$.

\section{DISCUSSION}

In the present study, the authors observed a decrease in the diameters of the quadruple hamstring grafts over the short term between the surgery and the post-operative measurement of the graft using MRI. On average, our results revealed a decrease of $9.68 \%$ in the graft diameter up to two weeks after surgery. The observed diameter decrease means that the size of the graft used during the ACL reconstruction of the knee will decrease even in the short term, possibly increasing the chances of graft failure in this period.

Currently, there are no studies in the literature that have evaluated the variation in graft sizes in the immediate post-operative period. Some authors suggested the possibility of measuring the size of the graft before surgery using MRI and ultrasonography $(5,23)$. However, the present assessment is the first, in our knowledge, that identified changes that occurred shortly after ACL reconstruction. The authors postulate that these changes may be caused by the pull force applied to the graft during tibial fixation with the interference screw. Because it is an elastic structure, the graft is elongated when being pulled. This can result in an increase in its length, and decrease in its diameter.

Previous literature using nuclear biopsies has reported that hamstring autografts begin to exhibit histological signs of neovascularization at two weeks after surgery and that the central necrosis process that occurs is mediated by cytokines. Despite this remodeling process, much of the original structure is preserved. $(10,15)$ According to these authors, replacement of the original cells occurs between the second and fourth week following surgery $(11,18)$. Therefore, the authors do not believe that the observed decrease in the size of the graft resulted from a structural modification (3). Furthermore, the tension applied to the graft during tibial fixation can create a deformity in the axial axis that could change the diameter of the graft. It is important to complete ACL reconstruction with a graft of sufficient diameter to allow for a satisfactory evolution and maturation, and minimizes the risks of rupture caused by graft insufficiency (17). Previous studies have shown that grafts with a diameter greater than $8 \mathrm{~mm}$ are less likely to fail (16). Based on the results obtained in the present study, there is a reduction in the size of the graft that occurs after fixation compared to pre-fixation measurements. Therefore, greater attention should be paid during graft preparation to ensure sufficient thickness before fixation. Based on this knowledge, grafts with smaller diameters (less than $8 \mathrm{~mm}$ ) are more likely to result in failure (16). Surgeons should consider strengthening, or conversion of the quadruple graft into a five- or six-fold conformation, when graft thickness is found to be insufficient (16). 
The study population examined in this study was sufficient to obtain significant results. The majority of the patients were male, which is consistent with the literature describing ACL rupture epidemiology $(1,4,22)$. There was no difference in measured graft diameter in terms of the side of operation. Furthermore, similar magnitudes of change in diameter were found across all study participants $(7.9 \mathrm{~mm}$ to 7.1 $\mathrm{mm}$ ), which indicates the observed decrease in this study can be used to predict changes that will occur over the first two weeks post-operatively.

The authors acknowledge some limitations to the present study. First, although the findings were validated by comparison between two different measurement modalities - namely intra-operative, in vivo examinations, and MRI examinations - we believe that these measurements are accurate and repre-

\section{REFERENCES}

1. Arliani GG, Astur DC, Kanas M, Kaleka CC, Cohen M. Anterior cruciate ligament injury: treatment and rehabilitation. Current perspectives and trends. Rev Bras Ortop 2012; 47(2):191-196.

2. Astur DC, Aleluia V, Veronese C, Astur N, Oliveira SG, Arliani GG, Badra R, Kaleka CC, Amaro JT, Cohen M. A prospective double blinded randomized study of anterior cruciate ligament reconstruction with hamstrings tendon and spinal anesthesia with or without femoral nerve block. Knee 2014; 21:911-915.

3. Astur DC, Arliani GG, Debieux P, Kaleka CC, Amaro JT, Cohen M. Intraarticular hamstring graft diameter decreases with continuing knee growth after ACL reconstruction with open physes. Knee Surg Sports Traumatol Arthrosc 2016; 24(3):792-795.

4. Astur DC, Santos CV, Aleluia V, Astur Neto N, Arliani GG, Kaleka CC, Skaf A, Cohen M. Characterization of cruciate ligament impingement: the influence of femoral or tibial tunnel positioning at different degrees of knee flexion. Arthroscopy 2013; 29(5):913-919.

5. Beyzadeoglu T, Akgun U, Tasdelen N, Karahan M. Prediction of semitendinosus and gracilis autograft sizes for ACL reconstruction. Knee Surg Sports Traumatol Arthrosc 2012; 20(7):1293-1297.

6. Butler DL, Noyes FR, Grood ES. Ligamentous restraints to anterior-posterior drawer in the human knee: A biomechanical study. J Bone Joint Surg Am 1980; 62(2):259-270.

7. Claes S, Verdonk P, Forsyth R, Bellemans J. The "ligamentization" process in anterior cruciate ligament reconstruction: what happens to the human graft? A systematic review of the literature. Am J Sports Med 2011; 39(11):2476-2483.

8. de Beus A, Koch JE, Hirschmann A, Hirschmann MT.How to evaluate bone tunnel widening after ACL reconstruction - a critical review. Muscles Ligaments Tendons J 2017; 7(2):230-239. doi: 10.11138/mltj/2017.7.2.230. eCollection 2017 Apr-Jun.

9. Erquicia JI, Gelber PE, Doreste JL, Pelfort X, Abat F, Monllau JC. How to improve the prediction of quadrupled semitendinosus and gracilis autograft sizes with magnetic reso- sentative. Future studies, such as a histological experiment in animals could prove whether there really are no alterations in the ligament composition before two weeks following surgery and exclude the possibility that the diameter decrease resulted from early necrosis of the cells around the neoligament.

\section{CONCLUSIONS}

The diameters of quadruple hamstrings knee grafts used for reconstructions of the anterior cruciate ligament decreased by $9.68 \%$ on average between the moment of the surgery and two weeks after surgery. This information can be used to guide graft preparation, reconstruction planning, rehabilitation and post-operative counseling of the patient as to their risk of rupture.

nance imaging and ultrasonography. Am J Sports Med 2013; 41(8):1857-1863.

10. Ferretti M, Cohen M, Fu FH. The fetal anterior anterior cruciate ligament: An anatomic and histologic study. Arthroscopy 2007; 23(3):278-283.

11. Fu F, Bennett C, Lattermann C, Ma CB. Current trends in anterior cruciate ligament reconstruction: Part 1: Biology and biomechanics of reconstruction. Am J Sports Med 1999; 27(6):821-830

12. Furman W, Marshall JL, Girgis FG. The anterior cruciate ligament: a functional analysis based on postmortem studies. J Bone Joint Surg Am 1976; 58(2):179-185.

13. Giorgio N, Moretti L, Pignataro P, Carrozzo M, Vicenti G, Moretti B. Correlation between fixation systems elasticity and bone tunnel widening after ACL reconstruction. Muscles Ligaments Tendons J 2016; 6(4):467-472. doi: 10.11138/ mltj/2016.6.4.467. eCollection 2016 Oct-Dec.

14. Girgis FG, Marshall JL, Al Monajem ARS. The cruciate ligaments of the knee joint. Anatomical, functional and experimental analysis. Clin Orthop Relat Res 1975; (106):216-231.

15. Leal MF, Astur DC, Debieux P, Arliani GG, Silveira Franciozi CE, Loyola LC, Andreoli CV, Smith MC, Pochini Ade C, Ejnisman B, Cohen M. Identification of Suitable Reference Genes for Investigating Gene Expression in Anterior Cruciate Ligament Injury by Using Reverse Transcription-Quantitative PCR. PLoS One 2015; 10(7): e0133323.

16. Magnussen RA, Lawrence JT, West RL, Toth AP, Taylor DC, Garrett WE, Graft size and patient age are predictors of early revision after anterior cruciate ligament reconstruction with hamstring autograft. Arthroscopy 2012; 28(4):526-531.

17. Mariscalco MW, Flanigan DC, Mitchell J, Pedroza AD, Jones MH, Andrish JT, Parker RD, Kaeding CC, Magnussen RA. The influence of hamstring autograft size on patient-reported outcomes and risk of revision after anterior cruciate ligament reconstruction: a Multicenter Orthopaedic Outcomes Network (MOON) Cohort Study Arthroscopy 2013; 29(12):1948-1953. 
18. Marumo K, Saito M, Yamagishi T, Fujii K. The "ligamentization" process in human anterior cruciate ligament reconstruction with autogenous patellar and hamstring tendons: a biochemical study. Am J Sports Med 2005; 33(8): 1166-1673.

19. Mathis DT, Rasch H, Hirschmann MT. In vivo bone tunnel remodeling in symptomatic patients after ACL reconstruction: a retrospective comparison of articular and extra-articular fixation. Muscles Ligaments Tendons J 2016; 5(4):31624. doi: 10.11138/mltj/2015.5.4.316.

20. Nebelung W, Becker R, Urbach D, Röpke M, Roessner A. Histological findings of tendon-bone healing following anterior cruciate ligament reconstruction with hamstring grafts. Arch Orthop Trauma Surg 2003; 123(4):158-163.
21. Pinczewski LA, Clingeleffer AJ, Otto DD, Bonar SF, Corry IS. Integration of hamstring tendon graft with bone in reconstruction of the anterior cruciate ligament. Arthroscopy 1997; 13(5):641-643.

22. Swenson DM, Collins CL, Best TM, Flanigan DC, Fields SK, Comstock RD. Epidemiology of knee injuries among U.S. high school athletes, 2005/2006-2010/2011. Med Sci Sports Exerc 2013; 45(3):462-469.

23. Xie G, Huangfu X, Zhao J. Prediction of the graft size of 4-stranded semitendinosus tendon and 4-stranded gracilis tendon for anterior cruciate ligament reconstruction: a Chinese Han patient study. Am J Sports Med 2012; 40(5):1161-1166. 